\title{
Effects of acute exercise on liver function and blood redox status in heavy drinkers
}

\author{
KALLIOPI GEORGAKOULI $^{1,2}$, EIRINI MANTHOU ${ }^{1,2}$, IOANNIS G. FATOUROS ${ }^{3}$, CHARIKLIA K. DELI $^{1,2}$, \\ DEMETRIOS A. SPANDIDOS ${ }^{4}$, ARISTIDIS M. TSATSAKIS ${ }^{5}$, DEMETRIOS KOURETAS ${ }^{6}$, \\ YIANNIS KOUTEDAKIS $^{1,2,7}$, YANNIS THEODORAKIS ${ }^{1}$ and ATHANASIOS Z. JAMURTAS ${ }^{1,2}$ \\ ${ }^{1}$ Department of Physical Education and Sport Science, University of Thessaly; ${ }^{2}$ Department of Kinesiology, \\ Institute for Research and Technology Thessaly, Karies, Trikala 42100; ${ }^{3}$ Department of Physical Education and \\ Sport Science, Democritus University, Komotini 69100; ${ }^{4}$ Laboratory of Clinical Virology, University of Crete \\ Medical School, Heraklion 71409; ${ }^{5}$ Department of Forensic Sciences and Toxicology, Medical School, University of Crete, \\ Heraklion 71003; ${ }^{6}$ Department of Biochemistry and Biotechnology, University of Thessaly, Larissa 41221, Greece; \\ ${ }^{7}$ School of Sports, Performing Arts and Leisure, University of Wolverhampton, Walsall, West Midlands WS1 3BD, UK
}

Received July 27, 2015; Accepted September 29, 2015

DOI: $10.3892 /$ etm.2015.2792

\begin{abstract}
Excessive alcohol consumption can induce oxidative stress, resulting in the development of several diseases. Exercise has been reported to prevent and/or improve a number of health issues through several mechanisms, including an improvement in redox status. It has also been previously suggested that exercise can help individuals with alcohol use disorders reduce their alcohol intake; however, research in this field is limited. The aim of the present study was to investigage the effects of acute exercise of moderate intensity on the liver function and blood redox status in heavy drinkers. For this purpose, a total of 17 heavy drinkers [age, 31.6 \pm 3.2 years; body mass index (BMI), 27.4 $\pm 0.8 \mathrm{~kg} / \mathrm{m}^{2}$; experimental group (EG)] and 17 controls [age, $33.5 \pm 1.3$ years; BMI, $26.1 \pm 1.4 \mathrm{~kg} / \mathrm{m}^{2}$; control group (CG), who did not exceed moderate alcohol consumption], underwent one trial of acute exercise of moderate intensity (50-60\% of the heart rate reserve) for $30 \mathrm{~min}$ on a cycle ergometer, following an overnight fast, and abstaining from smoking and alcohol consumption. Blood samples were obtained before and immediately after exercise for later determination of the indices of liver function and blood redox status. The subjects in the EG had significantly higher $(\mathrm{p}<0.05)$ baseline $\gamma$-glutamyl transferase $(\gamma$-GT) levels compared to the subjects in the CG. Exercise thus resulted in significantly higher $\gamma$-GT levels $(p<0.005)$ only in the EG. No significant
\end{abstract}

Correspondence to: Dr Athanasios Z. Jamurtas, Department of Physical Education and Sport Science, University of Thessaly, Karies, Trikala 42100, Greece

E-mail: ajamurt@pe.uth.gr

Key words: alcohol, excessive alcohol consumption, alcoholism, antioxidants, oxidative stress, training differences in aspartate aminotransferase (AST) and alanine aminotransferase (ALT) baseline levels were observed between the 2 groups. Following exercise, the AST levels increased significantly $(\mathrm{p}<0.001)$ in both groups, whereas the ALT levels increased significantly $(\mathrm{p}<0.01)$ only in the EG. The baseline glutathione $(\mathrm{GSH})$ levels were significantly lower $(\mathrm{p}<0.05)$ and remained low following exercise in the EG. In addition, we observed a trend for higher $(\mathrm{p}=0.07)$ baseline levels of thiobarbituric acid-reactive substances (TBARS), which remained elevated post-exercise in the EG compared to the CG. Significantly increased post-exercise total antioxidant capacity (TAC; $\mathrm{p}<0.01)$ and uric acid (UA; $\mathrm{p}<0.05)$ levels were noted in the CG, whereas the TAC $(\mathrm{p}=0.06)$ and UA $(\mathrm{p}=0.08)$ levels increased and approached significance post-exercise in the EG. No significant differences in the baseline levels of total bilirubin and protein carbonyl were observed between the 2 groups, even post-exercise. Thus, the findings of the present study indicate that even though heavy drinkers may be prone to oxidative stress, their exercise-induced antioxidant response is similar to that of individuals who do not drink heavily.

\section{Introduction}

Previous epidemiological studies have demonstrated that there is a dose-response association between alcohol use and the risk of several diseases and mortality. It has also been reported that light to moderate alcohol consumption has beneficial effects on many aspects of health, particularly on cardiovascular outcomes $(1,2)$. On the contrary, heavy alcohol consumption is considered to be responsible for hundreds of thousands of deaths annually worldwide. It is also known to be the cause of a number of diseases and is a precursor to injury and violence, and often leads to alcohol use disorders (AUDs) (alcohol abuse and dependence) $(3,4)$.

Oxidative stress results from an imbalance between oxidants and antioxidants in favor of the oxidants, leading to reversible redox modification of molecules involved in cellular 
signaling pathways, and damage to biological molecules (lipids, proteins and DNA) (5). Oxidative stress is responsible for the development of several pathological conditions, and it can be induced by numerous factors, including alcohol (6). Excessive, chronic alcohol consumption may lead to an impaired redox status, through both the increased production of reactive oxygen species (ROS) and impaired antioxidant defense mechanisms (7), and is associated with the pathogenesis of alcohol-related diseases, such as alcoholic liver disease, alcoholic cardiomyopathy and cancer (7,8). A number of studies have demonstrated that acute exercise can increase oxidative stress in humans (9-13). Exercise-induced oxidative stress activates signaling pathways that increase the expression of antioxidants and are also responsible for the process of exercise-induced adaptation $(11,13)$. This adaptation is influenced by various factors, including training volume, intensity, frequency and the mode of exercise (13).

Although it is not yet well established, exercise is a promising non-pharmaceutical intervention which may be used to reduce alcohol intake or even to help heavy drinkers and individuals with AUDs to stop excessive alcohol intake (14-16). Over the past 40 years, a small number of studies have investigated the effects of exercise on alcohol intake in individuals with AUDs $(15,16)$; however, only one recent study investigated the physiological responses to acute exercise in alcoholic patients. Jamurtas et al (17) examined the effects of low-intensity exercise on the urge to drink alcohol, the levels of $\beta$-endorphin $(\beta-E)$ and lactic acid, as well as the hematological parameters [complete blood count $(\mathrm{CBC})]$. Their results revealed that the pre-exercise levels of $\beta$-E were significantly lower in alcoholic patients, whereas exercise led to significantly $(\mathrm{p}<0.001)$ increased $\beta$-E levels only in alcoholic patients. Lactic acid and hematological parameters assessed through CBC did not differ between the 2 groups; however, exercise led to significantly increased levels of lactic acid, red blood cells, hemoglobin and hematocrit in both groups. Moreover, there was a $17 \%$ decrease in the urge to consume alcohol in the alcoholic patients. The results from this study indicate that a bout of low-intensity exercise affects endogenous opioids in alcoholic patients. Greater increases in $\beta$-E levels as a response to exercise of a different type and/or higher intensity has been observed in other specific populations (18). Since chronic excessive exposure to alcohol leads to decreased $\beta$-E production, which may be responsible for negative reinforcement (19), a greater increase in $\beta$-E levels after exercise may lead to a significant reduction in the urge to consume alcohol. Therefore, exercise may be used as a healthy alternative to alcohol intake. The effects of acute and chronic exercise of different intensities and types on the urge to consume alcohol and on the health status in individuals with AUDs, as well as the physiological mechanisms involved should thus be investigated.

Since there is gap in the literature on the acute effects of exercise on the metabolism and redox status in individuals with AUDs, the aim of the present study was to investigate the effects of acute exercise of moderate intensity on the indices of liver function and redox status in heavy drinkers. This is a preliminary step in describing the responses to exercise of individuals who consume alcholol excessively, in order to develop exercise training programmes that aim to halt alcohol abuse and improve health.

\section{Subjects and methods}

Subjects. A total of 17 heavy drinkers [age, 31.6 \pm 3.2 years; body mass index (BMI), 27.4 $\pm 0.8 \mathrm{~kg} / \mathrm{m}^{2}$; experimental group (EG)] and 17 controls that did not exceed moderate alcohol consumption [age, $33.5 \pm 1.3$ years; BMI, 26.1 $\pm 1.4 \mathrm{~kg} / \mathrm{m}^{2}$; control group $(\mathrm{CG})]$ participated in this study. All subjects were sedentary, and the level of physical activity was assessed with the International Physical Activity Questionnaire. The subjects in the 2 groups were also matched in terms of the number of cigarettes smoked per day.

Individuals with alcohol consumption levels exceeding the limits set by the National Institute on Alcohol Abuse and Alcoholism ( $>14$ drinks per week or $>4$ drinks per occasion for men, $>7$ drinks per week or $>3$ drinks per occasion for women) were identified as heavy drinkers. According to the National Institute on Alcohol Abuse and Alcoholism, exceeding these drinking limits significantly increases the risk of developing an AUD (4). Moreover, the Alcohol Use Disorders Identification Test (AUDIT) (20) was also used in order to identify individuals with AUDs. An AUDIT score between 8 and 15 indicates hazardous alcohol drinking, a score between 16 and 19 indicates harmful alcohol drinking, and a score of 20 or above indicates alcohol dependence (21). A total of 6 heavy drinkers had a score between 8 and 15, 5 heavy drinkers had a score between 16 and 19, and 6 heavy drinkers had a score of 20 or above (total AUDIT score, 17.65 \pm 1.25 ).

All subjects were informed about the study protocol, and the associated risks and benefits, and they signed an informed consent form prior to participation. Before proceeding with the other measurements, the medical history of the participants was reviewed and a resting electrocardiogram was performed in order to detect any heart abnormalities and contraindications to exercise. The procedures were in accordance with the 1975 Declaration of Helsinki, and ethics approval was obtained from the University of Thessaly Review Board (Larissa, Greece). Exclusion criteria included serious health issues, physical disabilities, or any other medical condition that contraindicated safe participation in exercise (e.g., a history of drug abuse other than alcohol or being over 60 years of age).

Experimental design. Subjects reported to our laboratory following an overnight fast, which included abstaining from both alcohol and smoking. The anthropometric and physiological characteristics of the study subjects were measured prior to exercise, and thereafter the subjects underwent one trial of acute exercise of moderate intensity (50-60\% of the heart rate reserve) for $30 \mathrm{~min}$ on a cycle ergometer (Monark Ergomedic 874E; Monark Exercise AB, Vansbro, Sweden). The heart rate (HR) was monitored during exercise by short-range telemetry (Polar RC3 GPS HR; Polar Electro Oy, Kempele, Finland). Blood samples were collected prior to and immediately following exercise for later determination of the indices of liver function $[\gamma$-glutamyl transferase $(\gamma-\mathrm{GT})$, aspartate aminotransferase (AST) and alanine aminotransferase (ALT) levels] and blood redox status [reduced glutathione (GSH), catalase activity, uric acid (UA), total antioxidant capacity (TAC), total bilirubin, thiobarbituric acid-reactive substances (TBARS) and protein carbonyl (PC) levels]. 
Blood sampling and handling. Blood samples $(15 \mathrm{ml})$ were drawn from a vein in the forearm and, in order to obtain plasma, a portion of the blood was placed in separate tubes, mixed with EDTA (20 $\mu \mathrm{l} / \mathrm{ml}$ of blood) and centrifuged at $1,370 \mathrm{x} \mathrm{g}$ for $10 \mathrm{~min}$ at $4^{\circ} \mathrm{C}$. The supernatant was aliquoted and stored at $-80^{\circ} \mathrm{C}$ for later determination of the TAC, TBARS and PC levels. For red blood cell lysate preparation, packed erythrocytes were diluted with distilled water $(1: 1 \mathrm{v} / \mathrm{v})$, vortexed vigorously, and centrifuged at 4,000 x g for $15 \mathrm{~min}$ at $4^{\circ} \mathrm{C}$. The supernatant was also aliquoted and stored at $-80^{\circ} \mathrm{C}$ for later analysis of catalase activity and GSH levels. Finally, more blood was collected in separate tubes containing clot activator, left at room temperature for $20 \mathrm{~min}$ to clot, and centrifuged at $1,370 \mathrm{x}$ for $10 \mathrm{~min}$ at $4^{\circ} \mathrm{C}$ in order to obtain serum. The supernatant was aliquoted and stored at $-80^{\circ} \mathrm{C}$ for later determination of the UA, total bilirubin, $\gamma-\mathrm{GT}$, AST and ALT levels.

Methods. Each variable was analyzed in duplicate on the same day. Samples went through only one freeze-thaw cycle.

Assays in plasma. TAC determination was based on the scavenging of 1,1-diphenyl-2-picrylhydrazyl (DPPH), as previously described in the study by Janaszewska and Bartosz (22). Plasma $(20 \mu \mathrm{l})$ was added to $480 \mu \mathrm{l}$ of $10 \mathrm{mM}$ sodium potassium phosphate ( $\mathrm{pH} 7.4)$ and $500 \mu \mathrm{l}$ of $0.1 \mathrm{mM}$ DPPH free radical. The samples were incubated in the dark for $30 \mathrm{~min}$ at room temperature. Subsequently, the samples were centrifuged at $20,000 \times \mathrm{g}$ for $3 \mathrm{~min}$ at $25^{\circ} \mathrm{C}$. The absorbance of the samples was read at $520 \mathrm{~nm}$. TAC is presented as $\mathrm{mM}$ of DPPH reduced to 1,1-diphenyl-2-picrylhydrazine (DPPH:H) by the antioxidants of plasma.

The TBARS levels were measured as previously described in the study by Keles et al (23). For TBARS determination, $100 \mu \mathrm{l}$ of plasma were added to $500 \mu \mathrm{l}$ of $35 \%$ TCA and $500 \mu \mathrm{l}$ of Tris- $\mathrm{HCl}$ (200 mM, pH 7.4). The samples were incubated for $10 \mathrm{~min}$ at room temperature. Subsequently, $1 \mathrm{ml}$ of $2 \mathrm{M} \mathrm{Na}_{2} \mathrm{SO}_{4}$ and $55 \mathrm{mM}$ thiobarbituric acid solution were added, and the samples were incubated for $45 \mathrm{~min}$ at $95^{\circ} \mathrm{C}$. The samples were then cooled on ice for $5 \mathrm{~min}$ and $1 \mathrm{ml}$ of $70 \%$ TCA was then added. The samples were vortexed and centrifuged at $15,000 \mathrm{x} \mathrm{g}$ for $3 \mathrm{~min}$ at $25^{\circ} \mathrm{C}$. The absorbance of the supernatant was read at $530 \mathrm{~nm}$. A baseline absorbance was taken into account by running a blank along with all samples during the measurement. The calculation of the TBARS concentration was based on the molar extinction coefficient of malondialdehyde, as previously described (23).

The PC levels were measured as previously described in the study by Patsoukis et al (24). For the determination of PC levels, $50 \mu \mathrm{l}$ of $20 \%$ TCA were added to $50 \mu \mathrm{l}$ of plasma. The samples were incubated in an ice bath for $15 \mathrm{~min}$ and centrifuged at $15,000 \mathrm{x} \mathrm{g}$ for $5 \mathrm{~min}$ at $4^{\circ} \mathrm{C}$. Subsequently, the supernatant was discarded, and $500 \mu \mathrm{l}$ of $10 \mathrm{mM}$ 2,4-dinitrophenylhydrazine (in $2.5 \mathrm{~N} \mathrm{HCl}$ ) for the sample or $500 \mu \mathrm{l}$ of $2.5 \mathrm{~N} \mathrm{HCl}$ for the blank was added to the pellet. The samples were incubated in the dark at room temperature for $1 \mathrm{~h}$, with intermittent vortexing every $15 \mathrm{~min}$. The samples were then centrifuged at $15,000 \mathrm{x} \mathrm{g}$ for $5 \mathrm{~min}$ at $4^{\circ} \mathrm{C}$. The supernatant was discarded, and $1 \mathrm{ml}$ of $10 \%$ TCA was added, vortexed and centrifuged at $15,000 \mathrm{x} \mathrm{g}$ for $5 \mathrm{~min}$ at $4^{\circ} \mathrm{C}$. The supernatant was discarded once again, and $1 \mathrm{ml}$ of ethanol:ethyl acetate $(1: 1 \mathrm{v} / \mathrm{v})$ was added, vortexed and centrifuged at $15,000 \mathrm{x}$ g for $5 \mathrm{~min}$ at $4^{\circ} \mathrm{C}$. This washing step was repeated twice. Finally, the supernatant was discarded, and $1 \mathrm{ml}$ of $5 \mathrm{M}$ urea (pH 2.3) was added, vortexed and incubated for $15 \mathrm{~min}$ at $37^{\circ} \mathrm{C}$. The samples were centrifuged at $15,000 \mathrm{x} \mathrm{g}$ for $3 \mathrm{~min}$ at $4^{\circ} \mathrm{C}$, and the absorbance was read at $375 \mathrm{~nm}$. The calculation of the protein carbonyl concentration was based on the molar extinction coefficient of dinitrophenylhydrazine, as previoulsy described (24).

Assays in red blood cell lysate. Catalase activity was determined as previously described in the study by Aebi (25). For the determination of catalase activity, $4 \mu \mathrm{l}$ of erythrocyte lysate (diluted 1:1) were added to $2991 \mu \mathrm{l}$ of $67 \mathrm{mM}$ sodium potassium phosphate ( $\mathrm{pH} 7.4)$. The samples were incubated at $37^{\circ} \mathrm{C}$ for $10 \mathrm{~min}$. Subsequently, $5 \mu \mathrm{l}$ of $30 \%$ hydrogen peroxide were added to the samples, and the change in absorbance was immediately read at $240 \mathrm{~nm}$ for $2 \mathrm{~min}$. The calculation of catalase activity was based on the molar extinction coefficient of $\mathrm{H}_{2} \mathrm{O}_{2}$, as previously described (25).

The GSH levels were determined as previously described by Reddy et al (26). A total of $20 \mu \mathrm{l}$ of erythrocyte lysate treated with $5 \%$ TCA was mixed with $660 \mu 1$ of $67 \mathrm{mM}$ sodium potassium phosphate (pH 8.0) and $330 \mu \mathrm{l}$ of $1 \mathrm{mM} \mathrm{5,5'-dithiobis-2}$ nitrobenzoate. The samples were then vortexed and incubated in the dark at room temperature for $45 \mathrm{~min}$. The absorbance of the samples was read at $412 \mathrm{~nm}$, as previously described (26). The GSH concentration was calculated by calibration curves constructed using commercial standards.

Hemoglobin in red blood cell lysate was determined using a commercially available kit (Dutch Diagnostics BV, Zutphen, The Netherlands), in order to estimate the final levels of GSH and catalase activity. For the determination of hemoglobin, $10 \mu 1$ of erythrocyte lysate treated with 5\% TCA were mixed with $2500 \mu \mathrm{l}$ of working reagent ( $\mathrm{pH} \mathrm{7.3;} \mathrm{diluted} \mathrm{1:10).} \mathrm{The} \mathrm{samples}$ were immediately vortexed and left for at least $3 \mathrm{~min}$ at $25^{\circ} \mathrm{C}$.

Assays in serum. The UA, total bilirubin, $\gamma$-GT, AST and ALT levels were measured on a Clinical Chemistry Analyzer Z 1145 (Zafiropoulos Diagnostica, Athens, Greece) using commercially available kits (Zafiropoulos Diagnostica). For the determination of UA levels, $6 \mu \mathrm{l}$ of serum were added to $600 \mu \mathrm{l}$ of working reagent. The samples were incubated for $1 \mathrm{~min}$ at $37^{\circ} \mathrm{C}$ and then their absorbance was read at $340 \mathrm{~nm}$. For the determination of $\gamma$-GT levels, $70 \mu \mathrm{l}$ of serum were added to $600 \mu \mathrm{l}$ of working reagent. The samples were incubated for $1 \mathrm{~min}$ at $37^{\circ} \mathrm{C}$ and then their absorbance was read at $405 \mathrm{~nm}$. For the determination of AST levels, $70 \mu \mathrm{l}$ of serum were added to $600 \mu \mathrm{l}$ of working reagent. The samples were incubated for $1 \mathrm{~min}$ at $37^{\circ} \mathrm{C}$ and their absorbance was then read at $340 \mathrm{~nm}$. For the determination of ALT levels, $70 \mu \mathrm{l}$ of serum were added to $600 \mu \mathrm{l}$ of working reagent. The samples were incubated for $1 \mathrm{~min}$ at $37^{\circ} \mathrm{C}$ and their absorbance was then read at $340 \mathrm{~nm}$.

The intra-assay coefficients of the variation for GSH, catalase, TAC, UA, total bilirubin, TBARS, PC, $\gamma$-GT, AST and ALT levels were 2.21, 3.38, 2.44, 2.75, 3.81, 2.10, 1.53, 1.15, 1.76 and 2.19 , respectively.

Statistical analysis. Two-way (time x group) repeated measures ANOVA was conducted to examine the differences in the indices of liver function and blood redox status. If a significant interaction was noted, pairwise comparisons were performed through simple contrasts and simple main effects analysis 
Table I. Anthropometric, physiological and other characteristics of the subjects (mean $\pm \mathrm{SE}$ ).

\begin{tabular}{lcc}
\hline Variables & EG & CG \\
\hline Age, years & $31.6 \pm 3.2$ & $33.5 \pm 1.3$ \\
Height, $\mathrm{cm}$ & $175.1 \pm 1.9$ & $170.3 \pm 2.1$ \\
Weight, $\mathrm{kg}$ & $84.3 \pm 3.4$ & $76.4 \pm 4.9$ \\
BMI, $\mathrm{kg} / \mathrm{m}^{2}$ & $27.4 \pm 0.8$ & $26.1 \pm 1.4$ \\
WHR & $0.90 \pm 0.03^{\mathrm{a}}$ & $0.82 \pm 0.02$ \\
Systolic BP, mm Hg & $122.1 \pm 2.7^{\mathrm{a}}$ & $111.7 \pm 3.8$ \\
Diastolic BP, mm Hg & $80.4 \pm 1.9$ & $77.4 \pm 2.4$ \\
Rest HR & $66.2 \pm 1.7$ & $65.3 \pm 1.4$ \\
Exercise HR & $128-139$ & $126-138$ \\
IPAQ & $1322.9 \pm 386.9$ & $1340.7 \pm 139.0$ \\
AUDIT score & $17.7 \pm 1.3^{\mathrm{a}}$ & $2.6 \pm 0.4$ \\
Cigarettes/day & $10.7 \pm 2.0$ & $10.9 \pm 3.5$ \\
\hline
\end{tabular}

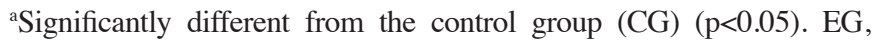
experimental group; BMI, body mass index; WHR, waist-to-hip ratio; BP, blood pressure; HR, heart rate; IPAQ, International Physical Activity Questionnaire; AUDIT, Alcohol Use Disorders Identification Test; SE, standard error.

using the Bonferroni correction. Moreover, an independent t-test was conducted to examine whether there were any differences between the baseline values of the anthropometric and physiological parameters. A p-value $<0.05$ was considered to indicate a statistically significant difference. The statistical programme used was SPSS version 18.0 (SPSS, Inc., Chicago, IL, USA). Data are presented as the means \pm standard error of the mean.

\section{Results}

Anthropometric, physiological and other characteristics. The waist-to-hip ratio (WHR) and systolic blood pressure $(\mathrm{SBP})$ values were significantly higher $(\mathrm{p}<0.05)$ in the EG compared to the CG (WHR, $0.90 \pm 0.03$ vs. $0.82 \pm 0.02$; SBP, $122.1 \pm 2,7$ vs. $111.7 \pm 3.8)$ and the AUDIT score was also much higher $(\mathrm{p}<0.05)$ in the EG than the CG $(17.7 \pm 1.3$ vs. $2.6 \pm 0.4$; Table I). The other anthropometric and physiological characteristics did not differ significantly between the 2 groups (Table I).

\section{Liver function variables}

$\gamma$-GT. There was a significant main effect of time (pre- and postexercise; $p<0.05)$, a significant main effect of group $(p<0.05)$ and a time $x$ group interaction $(p<0.05)$ for the $\gamma$-GT levels. The subjects in the EG had significantly higher $(\mathrm{p}<0.05)$ baseline $\gamma$-GT levels compared to subjects in the CG. Exercise thus resulted in significantly higher $\gamma$-GT levels $(\mathrm{p}<0.01)$ only in the EG (Fig. 1A).

$A S T$. No significant main effect of group or time $\mathrm{x}$ group interaction was observed for the AST levels; however, there was a significant main effect of time $(p<0.001)$. Pairwise comparisons indicated that the AST levels significantly increased $(p<0.001)$ post-exercise in both groups (Fig. 1B).
A

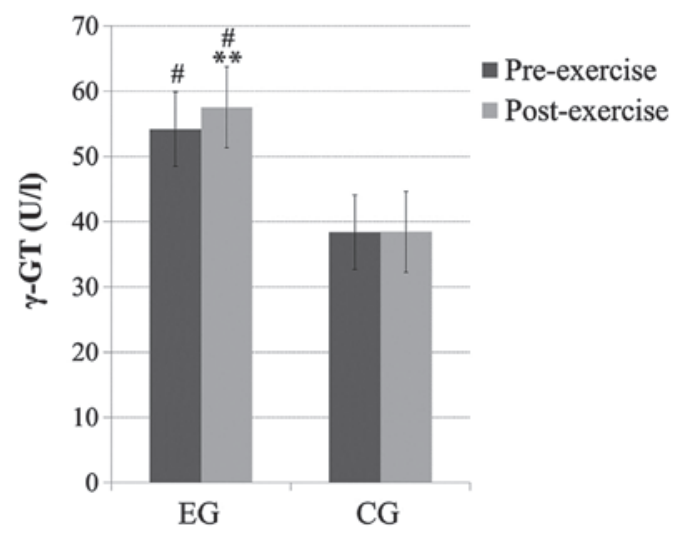

B

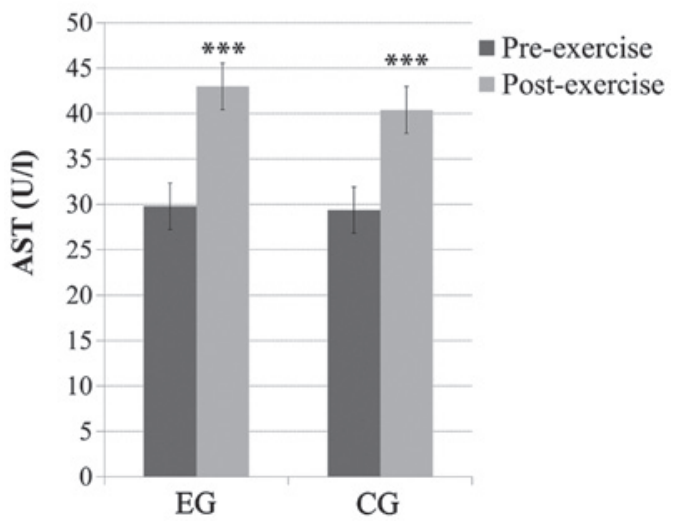

C

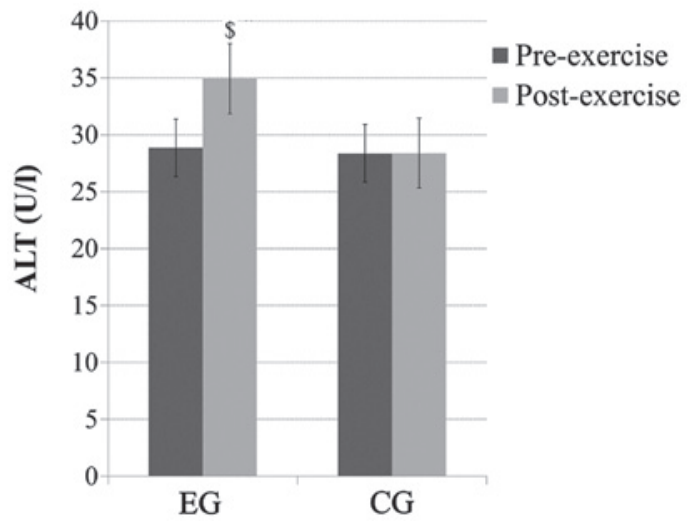

Figure 1. (A) $\gamma$-glutamyl transferase $(\gamma$-GT), (B) aspartate aminotransferase (AST) and (C) alanine aminotransferase (ALT) levels before and immediately after acute exercise in heavy drinkers [experimental group (EG)] and the control group (CG). ${ }^{* *}$ Significantly different from the pre-exercise value in the same group $(\mathrm{p}<0.01) ;{ }^{* * * *}$ significantly different from the pre-exercise value in the same

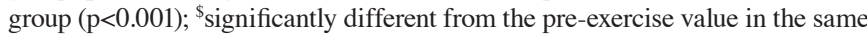
group $(\mathrm{p}<0.05)$; ${ }^{\#}$ significantly different from $\mathrm{CG}$ at the same time point $(\mathrm{p}<0.05)$.

$A L T$. No significant main effect of group was observed for the ALT levels; however, a significant main effect of time $(\mathrm{p}<0.05)$ and a time $\mathrm{x}$ group interaction $(\mathrm{p}<0.05)$ was observed. Pairwise comparisons indicated that the ALT levels increased significantly $(\mathrm{p}<0.01)$ post-exercise only in the EG (Fig. 1C).

\section{Redox status variables}

$G S H$. No significant main effect of time or time x group interaction was observed for the GSH levels; however, there was a significant main effect of group ( $<<0.05)$, with subjects in the 
A

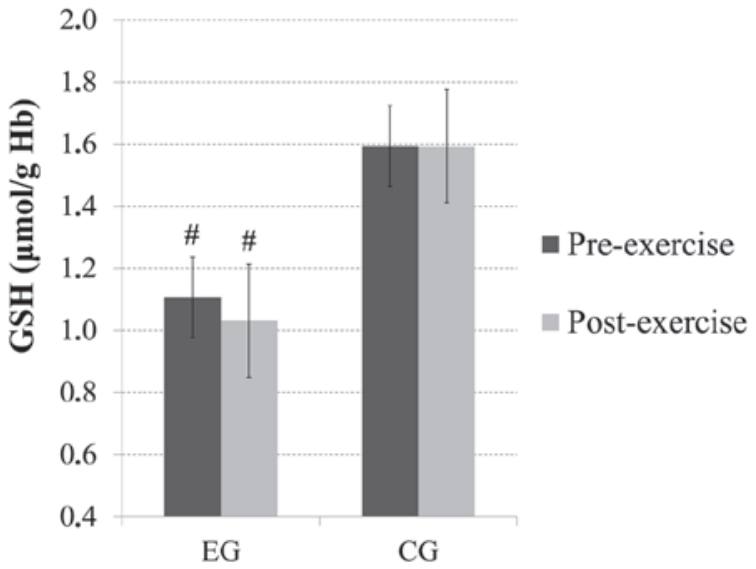

B

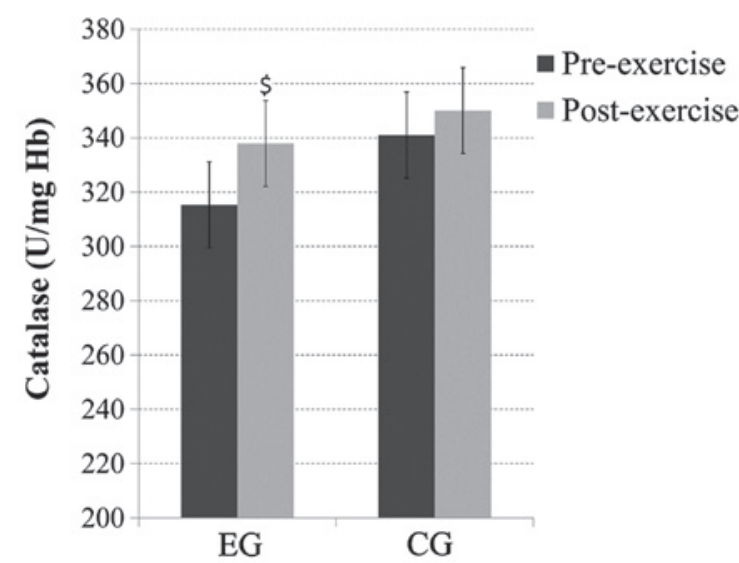

Figure 2. (A) Glutathione (GSH) and (B) catalase levels before and immediately after acute exercise in heavy drinkers [experimental group (EG)] and the control group (CG). ${ }^{\$}$ Significantly different from the pre-exercise value in the same group ( $\mathrm{p}<0.07)$; ${ }^{\#}$ significantly different from the $\mathrm{CG}$ at the same time point $(\mathrm{p}<0.05)$. Hb, hemoglobin.

EG exhibiting significantly lower GSH levels than the subjects in the CG before and after exercise (Fig. 2A).

Catalase. There was no significant main effect of group or time $\mathrm{x}$ group interaction for catalase; however, there was a trend $(\mathrm{p}=0.07)$ for a main effect of time. Pairwise comparisons revealed increased post-exercise catalase levels in the EG (Fig. 2B).

$T A C$. There was no significant main effect of group or time $\mathrm{x}$ group interaction for the TAC levels; however, there was a significant main effect of time, with significantly increased $(\mathrm{p}<0.01)$ post-exercise TAC levels in the CG and, similarly, a trend for increased $(\mathrm{p}=0.06)$ post-exercise TAC levels in the EG (Fig. 3A).

$U A$. There was no significant main effect of group or time $\mathrm{x}$ group interaction for the UA levels; however, there was a significant main effect of time $(\mathrm{p}<0.05)$, with significantly increased $(\mathrm{p}<0.05)$ post-exercise UA levels in the CG and a trend for increased $(\mathrm{p}=0.08)$ post-exercise UA levels in the EG (Fig. 3B).

Total bilirubin. No significant main effect of time, group or time $\mathrm{x}$ group interaction was detected for the total bilirubin levels (data not shown).

TBARS. No significant main effect of time or time $\mathrm{x}$ group interaction was observed for the TBARS levels; however, there
A

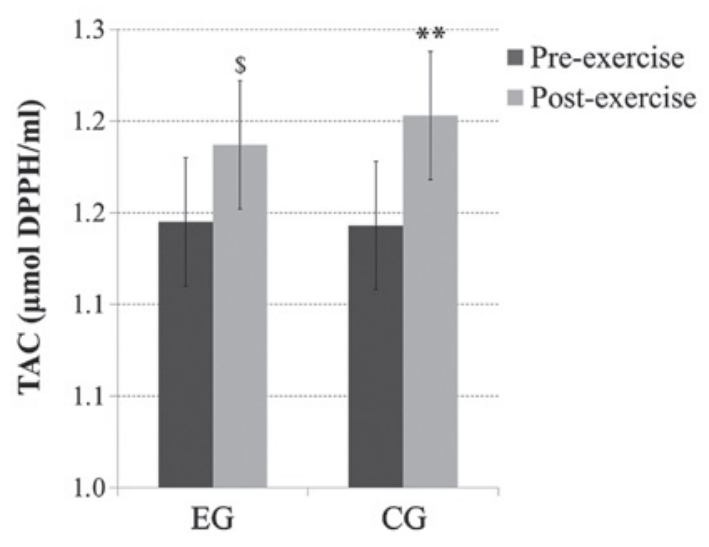

B

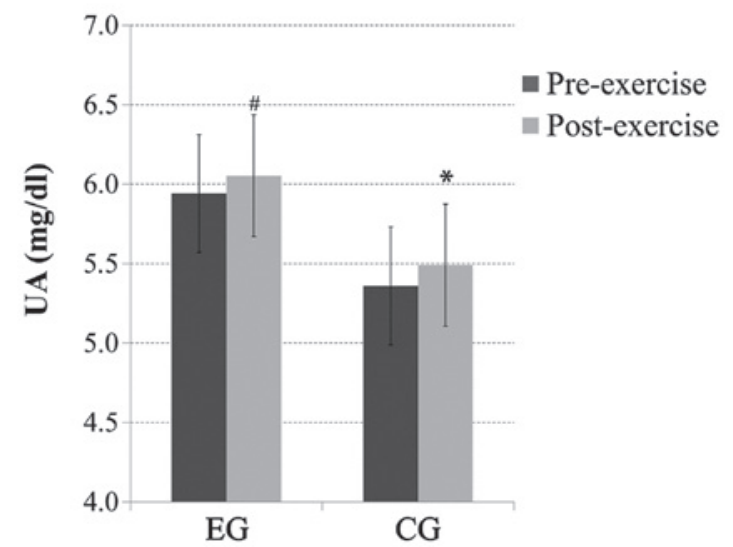

Figure 3. (A) Total antioxidant capacity (TAC) and (B) uric acid (UA) levels before and immediately after acute exercise in heavy drinkers [experimental group (EG)] and the control group (CG). "Significantly different from the pre-exercise value in the same group $(\mathrm{p}<0.05) ;{ }^{* *}$ significantly different from the pre-exercise value in the same group $(\mathrm{p}<0.01)$; " significantly different from the pre-exercise value in the same group $(\mathrm{p}=0.08)$; ${ }^{\$}$ significantly different from the pre-exercise value in the same group $(\mathrm{p}<0.06)$.

was a main effect of group $(\mathrm{p}=0.06)$. Pairwise comparisons revealed that there were increased baseline $(\mathrm{p}=0.08)$ and post-exercise ( $\mathrm{p}=0.06)$ TBARS levels in the subjects from the EG compared with the subjects from the CG (Fig. 4).

$P C$. There was no significant main effect of time, group or time $\mathrm{x}$ group interaction observed for the PC levels (data not shown).

\section{Discussion}

Liver function. To the best of our knowledge, this is the first study to investigate the effects of acute exercise on liver function and blood redox status in heavy drinkers. It has been well documented that chronic excessive exposure to alcohol can lead to liver inflammation, which may eventually impair liver function. A hypothesis of this study was that heavy drinkers would exhibit higher baseline levels of liver enzymes (mainly of $\gamma$-GT and ALT) and that exercise would lead to a further increase (mainly in AST).

$\gamma$-GT is a common index used in medicine for the detection of liver malfunction or issues with the bile ducts. Excessive alcohol consumption can also result in increased $\gamma$-GT levels. The results of the present study demonstrated that there were increased baseline levels of $\gamma$-GT in heavy drinkers compared to 


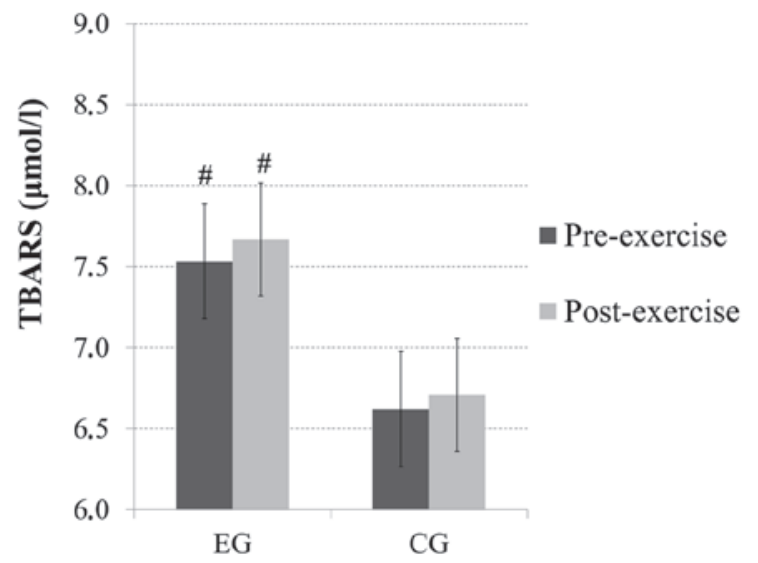

Figure 4. Total bilirubin, thiobarbituric acid-reactive substances (TBARS) levels before and immediately after acute exercise in heavy drinkers [experimental group (EG)] and the control group (CG). " "Significantly different from $\mathrm{CG}(\mathrm{p}=0.08)$ at baseline; significantly different from $\mathrm{CG}(\mathrm{p}=0.06)$ after exercise.

the controls. It is most likely that this finding is related to heavy drinking. Another factor that could, independently of alcohol intake, lead to increased $\gamma$-GT levels is cigarette smoking (27); however, heavy drinkers and controls had the same smoking habits and therefore most probably alcohol intake influenced the $\gamma$-GT levels.

AST and ALT are commonly used to detect inflammation and viral infections of the liver. AST is present in the liver and other tissues, including the skeletal muscles, and increased levels of AST indicate muscular inflammation. ALT is mainly found in the liver and in smaller amounts in other tissues, such as the kidneys and skeletal muscle, and thus increased levels of ALT are mainly attributable to liver inflammation (28). In this study, the baseline levels of AST and ALT were within the normal limits for men and women in both groups. It has previously been suggested that an increased BMI is an important contributing factor of increased liver enzyme levels in men (29); however, no significant difference in BMI between the heavy drinkers and controls was noted in the present study. On the other hand, a significantly increased WHR, which is indicative of increased visceral fat levels, was evident in heavy drinkers. We believe that differences in physiological (e.g., BMI and SBP) and biochemical parameters (e.g., $\gamma$-GT and ALT) that were found at the baseline are the result of heavy drinking.

Concerning liver enzyme responses to exercise, the $\gamma$-GT and ALT levels increased significantly only in the EG, whereas the AST levels increased in both groups after exercise. It is well known that exercise can result in transient increases in liver enzymes in healthy individuals, depending on the intensity, duration and type of exercise performed $(30,31)$. Thus, we hypothesized that heavy drinkers may be more prone to increased liver inflammation following moderate-intensity exercise due to increased oxidative stress.

Finally, the total bilirubin levels did not differ between groups and did not change after exercise. An increase in bilirubin levels in individuals at rest can indicate a number of liver function problems, whereas in healthy individuals it can be detected following intense exercise, due to hemolysis. Therefore, it is assumed that moderate-intensity exercise does not cause hemolysis in heavy drinkers, despite decreased blood
GSH levels that could render erythrocytes more susceptible to lipid peroxidation and consequently to hemolysis (32).

Taken together, the findings from the present study indicate that heavy drinking may have resulted in liver inflammation, which was enhanced by acute exercise. Although acute exercise can trigger increased liver inflammation in heavy drinkers, exercise training could lead to decreased levels of liver enzymes. Previous studies on clinical populations have demonstrated that exercise can ameliorate metabolic abnormalities. It has been found that aerobic exercise training may decrease liver enzyme levels in patients with liver diseases that are not caused by alcohol $(33,34)$. Training studies to examine the chronic effects of exercise on liver enzymes in individuals with AUDs are thus warranted.

Redox status. Excessive alcohol consumption may cause oxidative stress by both increasing ROS production and decreasing antioxidant defense mechanisms (7,35), and oxidative stress is also thought to be involved in the pathogenesis of alcohol-related diseases $(7,8)$. On the other hand, acute exercise results in increased production of ROS and also enhances antioxidant defense mechanisms $(11,13)$. Based on these facts, we hypothesized that heavy drinkers were more susceptible to oxidative stress compared to individuals who do not exceed moderate alcohol consumption, and that exercise leads to changes in indices of blood redox status in both groups, with heavy drinkers experiencing greater increases in oxidative stress after exercise. The results of this study indicate differences in redox status between heavy drinkers and healthy control, with the former exhibiting lower GSH and higher TBARS, an index of lipid peroxidation.

GSH is a major cellular thiol antioxidant with many functions that protect cells against oxidative stress and its consequences. Excessive exposure to alcohol can lead to GSH depletion and decreased antioxidant activity (36-38). It has been noted that chronic depletion of cytosolic GSH can lead to decreased levels of mitochondrial GSH (39). Alcohol is thought to contribute to GSH depletion in the mitochondria of hepatocytes by producing oxidative agents and also by inhibiting the mitochondrial GSH transporter (transport of GSH from the cytosol into mitochondria) $(6,40,41)$. Mitochondrial GSH may be of greater importance for hepatocyte survival than cytoplasmic GSH, as its depletion can result in increased production of $\mathrm{H}_{2} \mathrm{O}_{2}$ in mitochondria, thus causing oxidation of cytoplasmic proteins and affecting cell signaling (42). However, impaired redox status also influences changes in erythrocytes and can lead to decreased levels of blood GSH. It has previously been reported that individuals with alcohol-related liver diseases exhibit low levels of blood GSH (36-38). Although heavy drinkers who participated in this study did not exhibit greater than normal levels of $\gamma$-GT, blood GSH levels were significantly lower than those of controls. Findings from the present study indicate that heavy drinkers and individuals with AUDs without clinical signs of liver dysfunction may experience lower blood GSH levels than individuals who do not exceed moderate alcohol consumption.

An impaired redox status can lead to DNA damage, protein modification and lipid peroxidation. Blood redox status indices usually reflect the overall status of the body, and we would thus expect to observe differences between the two groups in the 
present study. Baseline and post-exercise levels of TBARS which act as an index of lipid peroxidation, were higher in heavy drinkers than the controls in this study. This result has been reported previously in alcoholics and suggests that alcohol abuse results in enhanced lipid peroxidation, which in turn leads to increased fragility of the cell membranes $(6,37,43)$.

In the present study, the exercise-induced antioxidant response was found to be higher in healthy controls than heavy drinkers, as indicated by post-exercise changes in TAC and UA. Heavy drinkers may not respond well to exercise-induced oxidative stress due to lower antioxidant defenses (35). However, it is not clear as to whether this antioxidant response in heavy drinkers increases some hours after exercise. Changes in these indices at more time points after exercise should therefore be examined.

Oxidative stress can alter membrane permeability and lead to hemolysis (44); however, we noted that exercise did not lead to hemolysis in heavy drinkers regardless of the increased oxidative stress. This could be explained by the intensity of the exercise used in the present study and also by the fact that antioxidant responses to exercise were increased in a similar fashion to those of the controls.

In conclusion, taken together, the findings of the present study suggest that excessive alcohol consumption causes low baseline GSH and increased $\gamma$-GT and TBARS levels. Acute aerobic exercise increases the responses of liver enzymes in heavy drinkers, whereas the elevated antioxidant responses following the aerobic bout of exercise in heavy drinkers are somewhat attenuated compared to healthy controls. More post-exercise time points would provide a better understanding of the way individuals with AUDs respond to exercise. Finally, since exercise training has been proposed as a useful and safe strategy in the treatment of AUDs, future research should focus on training exercise interventions which aim to reduce alcohol consumption and would prevent or ameliorate alcohol-related liver damage.

\section{Acknowledgements}

This study was co-financed by the European Union [European Social Fund (ESF)] and Greek national funds through the Operational Program 'Education and Lifelong Learning' of the National Strategic Reference Framework-Research Funding Program: THALES. Investing in knowledge society through the ESF.

\section{References}

1. Brien SE, Ronksley PE, Turner BJ, Mukamal KJ and Ghali WA Effect of alcohol consumption on biological markers associated with risk of coronary heart disease: systematic review and meta-analysis of interventional studies. BMJ 342: d636, 2011.

2. Ronksley PE, Brien SE, Turner BJ, Mukamal KJ and Ghali WA: Association of alcohol consumption with selected cardiovascular disease outcomes: a systematic review and meta-analysis. BMJ 342: d671, 2011.

3. National Institute for Alcohol Abuse and Alcoholism: Drinking Levels Defined. http://www.niaaa.nih.gov/alcohol-health/ overview-alcohol-consumption moderate-binge-drinking. Retrieved Jan 10, 2014.

4. Greenfield TK, Ye Y, Bond J, Kerr WC, Nayak MB, Kaskutas LA, Anton RF, Litten RZ and Kranzler HR: Risks of alcohol use disorders related to drinking patterns in the U.S. general population. J Stud Alcohol Drugs 75: 319-327, 2014.
5. Sies H and Jones D: Oxidative stress. In: Encyclopedia of Stress. Fink G (ed). Vol 3. 2nd edition. Elsevier, Amsterdam, pp45-48, 2007.

6. Das SK and Vasudevan DM: Alcohol-induced oxidative stress. Life Sci 81: 177-187, 2007.

7. Zima T and Kalousová M: Oxidative stress and signal transduction pathways in alcoholic liver disease. Alcohol Clin Exp Res 29 (Suppl 11): 110S-115S, 2005.

8. Tsukamoto $\mathrm{H}$ and Lu SC: Current concepts in the pathogenesis of alcoholic liver injury. FASEB J 15: 1335-1349, 2001.

9. Davies KJ, Quintanilha AT, Brooks GA and Packer L: Free radicals and tissue damage produced by exercise. Biochem Biophys Res Commun 107: 1198-1205, 1982.

10. Finaud J, Lac G and Filaire E: Oxidative stress: relationship with exercise and training. Sports Med 36: 327-358, 2006.

11. Coffey VG and Hawley JA: The molecular bases of training adaptation. Sports Med 37: 737-763, 2007.

12. Michailidis Y, Jamurtas AZ, Nikolaidis MG, Fatouros IG, Koutedakis Y, Papassotiriou I and Kouretas D: Sampling time is crucial for measurement of aerobic exercise-induced oxidative stress. Med Sci Sports Exerc 39: 1107-1113, 2007.

13. Steinbacher P and Eckl P: Impact of oxidative stress on exercising skeletal muscle. Biomolecules 5: 356-377, 2015.

14. Read JP and Brown RA: The role of physical exercise in alcoholism treatment and recovery. Prof Psychol Res Pract 34: 49-56, 2003.

15. Zschucke E, Heinz A and Ströhle A: Exercise and physical activity in the therapy of substance use disorders. ScientificWorldJournal 2012: 901741, 2012.

16. Giesen ES, Deimel H and Bloch W: Clinical exercise interventions in alcohol use disorders: a systematic review. J Subst Abuse Treat 52: 1-9, 2015

17. Jamurtas AZ, Zourbanos N, Georgakouli K, Georgoulias P, Manthou E, Fatouros IG, Goudas M, Koutedakis Y and Theodorakis Y: Beta endorphin and alcohol urge responses in alcoholic patients following an acute bout of exercise. J Addict Res Ther 5: 1000194, 2014.

18. Goldfarb AH and Jamurtas AZ: Beta-endorphin response to exercise. An update. Sports Med 24: 8-16, 1997.

19. Gianoulakis C: Endogenous opioids and addiction to alcohol and other drugs of abuse. Curr Top Med Chem 4: 39-50, 2004

20. Moussas G, Dadouti G, Douzenis A, Poulis E, Tzelembis A, Bratis D, Christodoulou C and Lykouras L: The Alcohol Use Disorders Identification Test (AUDIT): reliability and validity of the Greek version. Ann Gen Psychiatry 8: 11, 2009.

21. World Health Organization: The Alcohol Use Disorders Identification Test: Guidelines for Use in Primare Care. 2nd edition. WHO Press, Geneva, 2001.

22. Janaszewska A and Bartosz G: Assay of total antioxidant capacity: comparison of four methods as applied to human blood plasma. Scand J Clin Lab Invest 62: 231-236, 2002.

23. Keles MS, Taysi S, Sen N, Aksoy H and Akçay F: Effect of corticosteroid therapy on serum and CSF malondialdehyde and antioxidant proteins in multiple sclerosis. Can J Neurol Sci 28: 141-143, 2001.

24. Patsoukis N, Zervoudakis G, Panagopoulos NT, Georgiou CD, Angelatou F and Matsokis NA: Thiol redox state (TRS) and oxidative stress in the mouse hippocampus after pentylenetetrazol-induced epileptic seizure. Neurosci Lett 357: 83-86, 2004.

25. Aebi H: Catalase in vitro. Methods Enzymol 105: 121-126, 1984.

26. Reddy YN, Murthy SV, Krishna DR and Prabhakar M: Role of free radicals and antioxidants in tuberculosis patients. Indian $\mathrm{J}$ Tuberc 51: 213-218, 2004.

27. Whitehead TP, Robinson D and Allaway SL: The effects of cigarette smoking and alcohol consumption on serum liver enzyme activities: a dose-related study in men. Ann Clin Biochem 33: 530-535, 1996.

28. Banfi G, Colombini A, Lombardi G and Lubkowska A: Metabolic markers in sports medicine. Adv Clin Chem 56: 1-54, 2012.

29. Robinson D and Whitehead TP: Effect of body mass and other factors on serum liver enzyme levels in men attending for well population screening. Ann Clin Biochem 26: 393-400, 1989.

30. Halonen PI and Konttinen A: Effect of physical exercise on some enzymes in the serum. Nature 193: 942-944, 1962.

31. Parikh DJ and Ramanathan NL: Exercise induced serum enzyme changes in untrained subjects. Indian J Physiol Pharmacol 21: 175-180, 1977.

32. Fibach E and Rachmilewitz E: The role of oxidative stress in hemolytic anemia. Curr Mol Med 8: 609-619, 2008. 
33. Cho J, Lee I, Kim D, Koh Y, Kong J, Lee S and Kang H: Effect of aerobic exercise training on non-alcoholic fatty liver disease induced by a high fat diet in C57BL/6 mice. J Exerc Nutrition Biochem 18: 339-346, 2014.

34. Keating SE, Hackett DA, Parker HM, O'Connor HT, Gerofi JA Sainsbury A, Baker MK, Chuter VH, Caterson ID, George J and Johnson NA: Effect of aerobic exercise training dose on liver fat and visceral adiposity. J Hepatol 63: 174-182, 2015.

35. Tseng YM, Tsai SM, Lin CC, Jin YR, Yeh WH, Hsiao JK, Chen CF, Lan WH and Tsai LY: Oxidative stress-related enzyme polymorphisms associated with the immunological biomarkers levels in heavy drinkers in Taiwan. J Clin Lab Anal 27: 494-503, 2013.

36. Loguercio C, Blanco FD, De Girolamo V, Disalvo D, Nardi G, Parente A and Blanco CD: Ethanol consumption, amino acid and glutathione blood levels in patients with and without chronic liver disease. Alcohol Clin Exp Res 23: 1780-1784, 1999.

37. Maithreyi R, Janani AV, Krishna R, Shweta A, Edwin RR and Mohan SK: Erythrocyte lipid peroxidation and antioxidants in chronic alcoholics with alcoholic liver disease. Asian J Pharm Clin Res 3: 183-185, 2010.
38. Gupta S, Pandey R, Katyal R, Aggarwal HK, Aggarwal RP and Aggarwal SK: Lipid peroxide levels and antioxidant status in alcoholic liver disease. Indian J Clin Biochem 20: 67-71, 2005.

39. Meister A: Mitochondrial changes associated with glutathione deficiency. Biochim Biophys Acta 1271: 35-42, 1995.

40. Viña J, Estrela JM, Guerri C and Romero FJ: Effect of ethanol on glutathione concentration in isolated hepatocytes. Biochem J 188: $549-552,1980$

41. Fernández-Checa JC, García-Ruiz C, Colell A, Morales A, Marí M, Miranda M and Ardite E: Oxidative stress: role of mitochondria and protection by glutathione. Biofactors 8: 7-11, 1998.

42. Han D, Hanawa N, Saberi B and Kaplowitz N: Mechanisms of liver injury. III. Role of glutathione redox status in liver injury. Am J Physiol Gastrointest Liver Physiol 291: G1-G7, 2006.

43. Barden A, Zilkens RR, Croft K, Mori T, Burke V, Beilin LJ and Puddey IB: A reduction in alcohol consumption is associated with reduced plasma F2-isoprostanes and urinary 20-HETE excretion in men. Free Radic Biol Med 42: 1730-1735, 2007.

44. Lubin B and Chiu D: Properties of vitamin E-deficient erythrocytes following peroxidant injury. Pediatr Res 16: 928-932, 1982. 